\title{
Research on water jet cutting of composites ba- sed on epoxy/microparticles from coconut shell
}

\author{
Miroslav Müller ${ }^{1, *}$, Petr Valášek ${ }^{1}$, Miloslav Linda $^{2}$, Viktor Koláŕr ${ }^{1}$ \\ ${ }^{1}$ Czech University of Life Sciences Prague, Faculty of Engineering, Department of Material Science \\ and Manufacturing Technology, Kamýcká 129, Praha 6 - Suchdol, Czech Republic \\ ${ }^{2}$ Czech University of Life Sciences Prague, Faculty of Engineering, Department of Electrical \\ Engineering and Automation, Kamýcká 129, Praha 6 - Suchdol, Czech Republic,
}

\begin{abstract}
The paper deals with a machining of polymeric composite materials with a reinforcement based on a waste from a coconut processing, i.e. a coconut shell by means of an unconventional technology, i.e. a water jet (WJ). These composite systems are desirable in the material engineering. Not only the research of their subsequent mechanical properties is important, but also searching for effective ways of machining and dividing to required shape and size. The composite material was tested in a form of boards made by means of a vacuum infusion. The aim of the research is to study an influence of the abrasive water jet and water jet at its impact on a surface of the machined polymeric composite material. The research was proved on CNC cutting machine AWJ CT 0806. Cutting conditions, i.e. various traverse speeds 50, 100, 250, 500,750 and $1000 \mathrm{~mm} / \mathrm{min}$, an influence of cutting by the water jet with abrasive particles and without them on an integrity of the tested material and the surface topography were evaluated within the research. A surface analysis is also evaluated by means of a scanning electron microscopy (SEM) depending on a traverse speed and a mass flow of the abrasive grains.
\end{abstract}

Keywords: abrasive water jet, traverse speed, kerf width, SEM, water jet

\section{Introduction}

Composite materials with natural phases /a filler have been developed in a present in the material engineering. The natural filler is used in a form of microparticle filler or plant / animal fibres.

A substitution of synthetic fillers/reinforcements with natural ones is important in the material research. Biocomposites are also made with the use of various other ingredients, e.g. egg shell [1, 2, 3], seeds of Phoenix [4], Ensete ventricosum [5], oil palm fibres [6, 7], sisal fibres $[8,9]$, flax $[10,11]$ and other narural fibres (cellulose fibres, rice - husk, jute etc.) [12, $13,14]$. Many research studies deal with mechanical properties of composite materials. However, it is necessary to focus also on other operations in an engineering production, i.e. material dividing and subsequent machining [15]. The material dividing is a common attribute of production companies [16]. Classically applied methods of machining are not

\footnotetext{
* Corresponding author: muller@tf.czu.cz
}

Reviewers: Anna Mičietová, Sergej Hloch 
always technically and economically the most suitable for machining of new materials [17]. Various variants of cutting by means of a water jet technology belong among prospective methods of the composite materials dividing.

It does not come to a heat affecting of machined materials, to an evaporation and to a degradation of the material. A temperature is a problematic factor mainly at machining of polymers and polymeric composites. The liquid-jet is the working tool for the machining. It is completed with an ingredient of abrasive substances at the abrasive water jet technology [16]. This technology consists in a principle of generating high water pressure which goes through a nozzle of a small diameter so the water gains very high kinetic energy similarly as at the water jet [17-19]. Abrasive particles several fold increasing its effect are added into the high-speed water stream [16]. An interaction between a matrix and a reinforcement can be failed at acting of high-speed liquid with abrasive grains with the surface of the workpiece at the composite materials cutting [19-20]. The AWJ technology proved to cut in the effective way also the reinforcing glass fabric, corundum and glass-bead particles without their delamination from the matrix. The delamination and significant removal of the material show themselves in the first stage of the cutting. Subsequent cut is regular [21]. However, the results proved the delamination of layers at various traverse speeds.

The aim of the research is to study an influence of the abrasive water jet and water jet at its impact on a surface of the machined polymeric composite material with the coconut shell microparticle filler.

\section{Methodology}

The filler from a woody shell of the coconut which is of brown colour and it is covered with peeling bay bundles was used for the research. The bay stays on the coconut as a remainder of a green packaging in which the coconut was originally placed during its growth and harvesting.

Waste from a food industry, i.e. the coconut shells were grinded and milled. Subsequently the microparticles of grinded coconut shells were fractionalised on vibrating sieves with a mesh size $200 \mu \mathrm{m}$. Microparticles were dried before the application at the temperature 105 ${ }^{\circ} \mathrm{C}$ for the time $24 \mathrm{~h}$.

A vacuum infusion was used for the production of the composite material. A twocomponent epoxy resin with a low viscosity suitable for a laminating technology including the vacuum infusion was used as the matrix. The resin was hardened with cycloaliphatic polyamine, the main component isophorone di-amine.

The water jet with a dash of abrasive grains (a garnet MESH 80) was used for the research. The research was performed on the device CNC cutting machine AWJ CT 0806 (fig. 1). The speed of the cut was 50,100, 250, 500, 750 and $1000 \mathrm{~mm} / \mathrm{min}$. The diameter of the nozzle was $0.8 \mathrm{~mm}$. The working pressure was $380 \mathrm{MPa}$. The water jet with the abrasive grains affected perpendicularly to the cutting edge of the sample. The distance of the nozzle above the cut material was $3 \mathrm{~mm}$.

Cuts of the composite material by water jet WJ technology and abrasive water jet AWJ technology at which the mass flow of the abrasive grains was $90.62 \pm 1.19 \mathrm{~g} / \mathrm{min}$ were tested within the research. The testing cut was made on the composite board of dimensions $90 \mathrm{x}$ $130 \mathrm{~mm}$. A length of the cut was $60 \mathrm{~mm}$.

A width of a kerf inlet (fig. 1 B) and outlet (fig. 1 C) of the abrasive water jet was evaluated within the research. It considerably differed. A parameter of the kerf width was evaluated by means of a stereoscopic microscope Arsenal SZP 11-T ZOOM which is equipped with a digital camera and an evaluating software Quick Industrial Photo 2.3. The evaluated kerf was measured in 30 places $10 \mathrm{~mm}$ from the beginning and the end of the cut. A thickness of the cut composite board was $4.5 \pm 0.1 \mathrm{~mm}$. A topography of the machined 
surface by means of a surface analysis by means of a scanning electron microscopy (SEM) depending on the traverse speed and AWJ or WJ technology was evaluated within the research. The measurement was performed on the scanning electron microscope TESCAN MIRA 3 GMX. SE detector were used for the measurement, the accelerating voltage was 5 $\mathrm{kV}$. The samples were dusted with gold by means of the equipment Quorum Q150R ES Sputtering Deposition Rate using Gold. Measured values were processed by means of statistical analysis methods by use of Anova F-test (p-values).
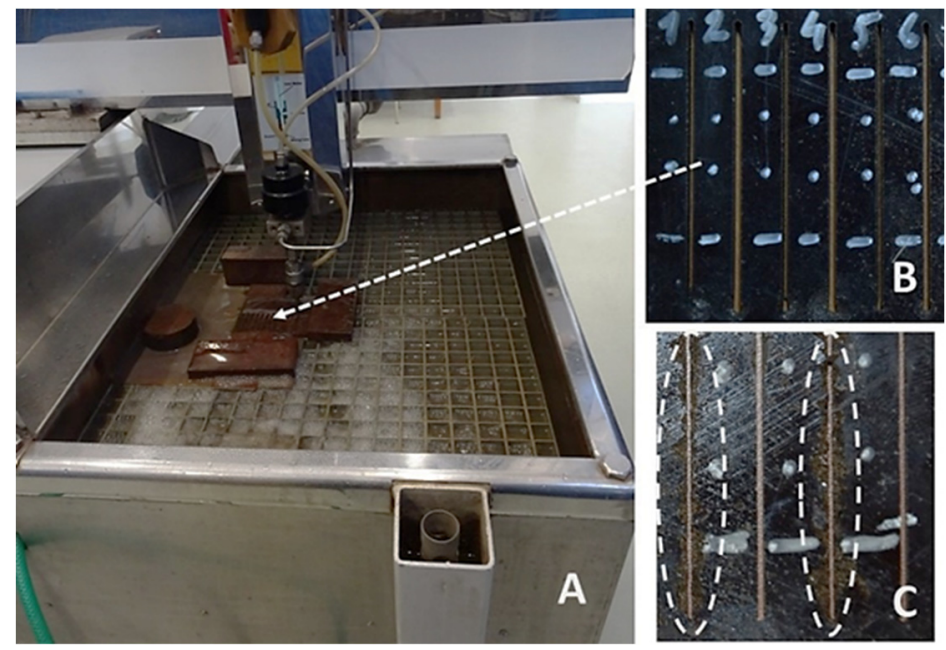

Fig. 1. Machining of composites based on epoxy / microparticles from coconut shell by means of water jet technology: A: CNC AWJ CT 0806, B: cut in tested composite sample - inlet of abrasive water jet, $\mathrm{C}$ : cut in tested composite sample - outlet of abrasive water jet

\section{Results}

Experiments results proved a quiddity of a combination of the traverse speed and the use of abrasive particles at dividing the biological reinforcement based composite materials. The composite reinforcement is evident from fig. 2. Fig. 2 A, B represent the microparticle filler on the basis of the woody coconut shells. The filler is of a specific shape which is visible in fig. 2 A, B. The bay fibre from the coconut shell is evident from fig. 2 C.

Results of a kerf width at cutting of the composite material by means of the water jet technology WJ are obvious from fig. 3. The kerf width inlet did not significantly differ depending on the traverse speed in the interval from 50 to $1000 \mathrm{~m} / \mathrm{min}$. The kerf width difference was maximum of $11.15 \%$. The kerf width outlet was of high influence depending on the traverse speed. The kerf width influence was 5.31 to $791.19 \%$. A significant destruction of the outlet side (fig. $1 \mathrm{C}$ ) occurred at higher speeds at cutting by means of the water jet without the abrasive grains. It was the speeds from $500 \mathrm{~mm} / \mathrm{min}$.

It is obvious from the statistical testing of the kerf width inlet and outlet that they are statistically non-homogeneous groups $(p=0.0000)$, i.e. there is the difference between the kerf width inlet and outlet in the significance level 0.05 .

Results of the kerf width at cutting of the composite material by means of AWJ technology are evident from fig. 4. The kerf width inlet did not significantly differ depending on the traverse speed in the interval from 50 to $1000 \mathrm{~mm} / \mathrm{min}$. The difference of the kerf width was maximum $15.31 \%$. More significant influence of the kerf width was outlet depending on the traverse speed. The difference in the kerf width was up $34.69 \%$. The 
difference was increasing with increasing traverse speed.

It is obvious from the statistical comparison of the kerf width inlet and outlet that they are statistically non-homogeneous groups $(p=0.0000)$, i.e. there is the difference in the kerf width inlet and outlet in the significance level 0.05. The influence of the traverse speed at AWJ as well as WJ technology was statistically proved $(\mathrm{p}=0.0000)$.
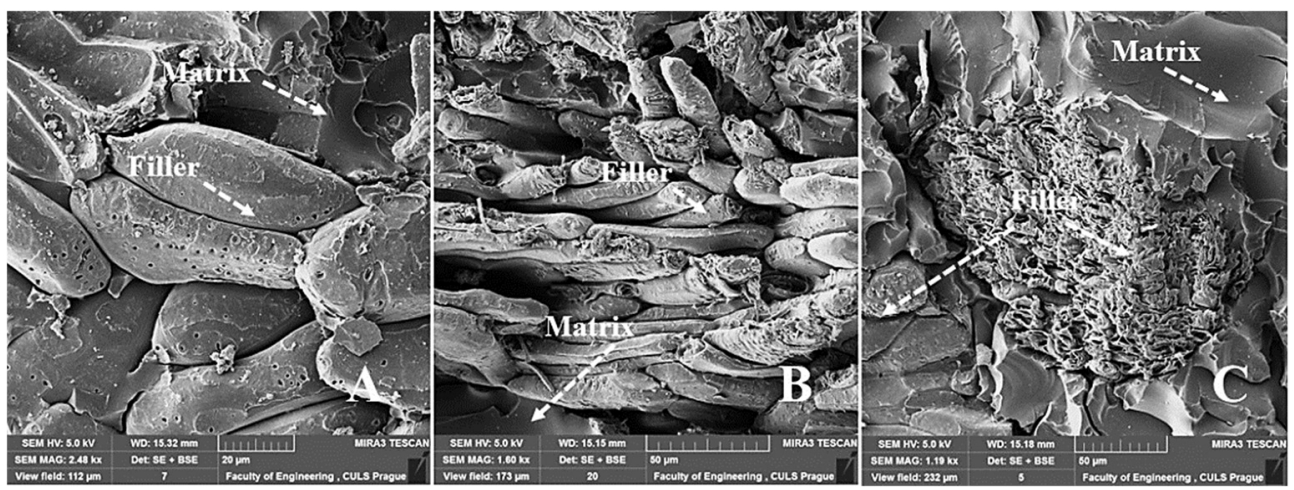

Fig. 2. SEM images of composite material with filler based on microparticles from coconut shell: A: microparticles of coconut woody shell - longitudinal orientation (MAG $2.48 \mathrm{kx}$ ), B: microparticles of coconut woody shell - transverse orientation (MAG $1.60 \mathrm{kx}$ ), C: bay fibre from coconut shell (MAG $1.19 \mathrm{kx})$

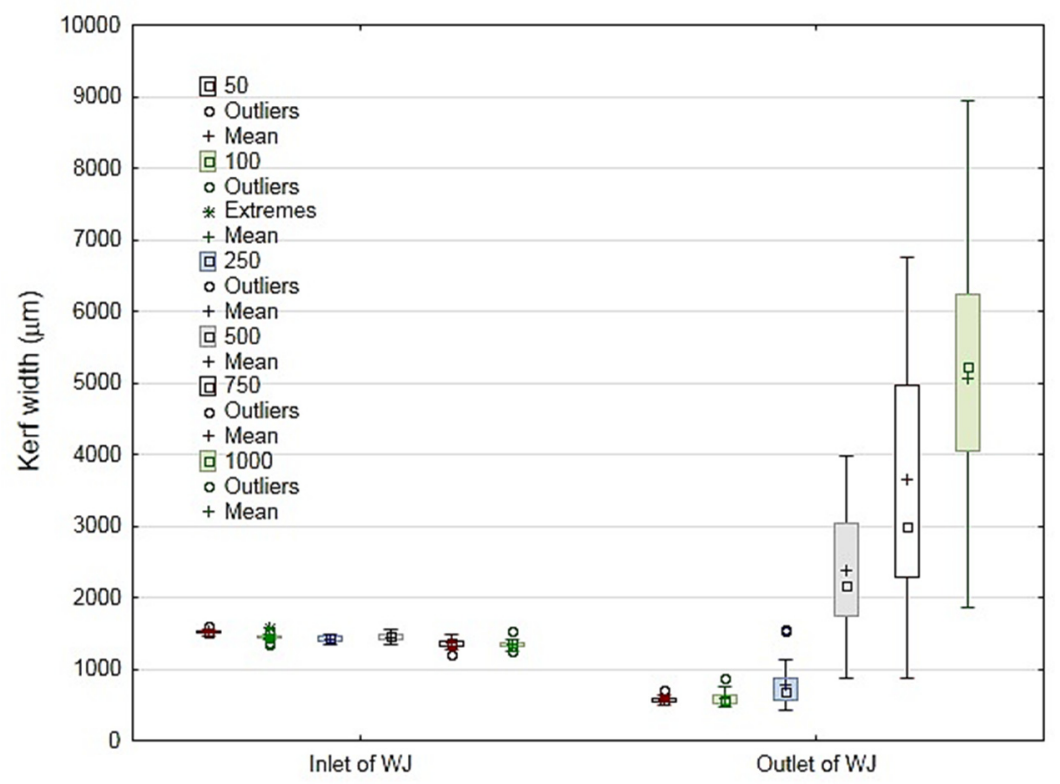

Fig. 3. Kerf width of cut by WJ technology of polymeric composite material with coconut shell microparticle based filler 


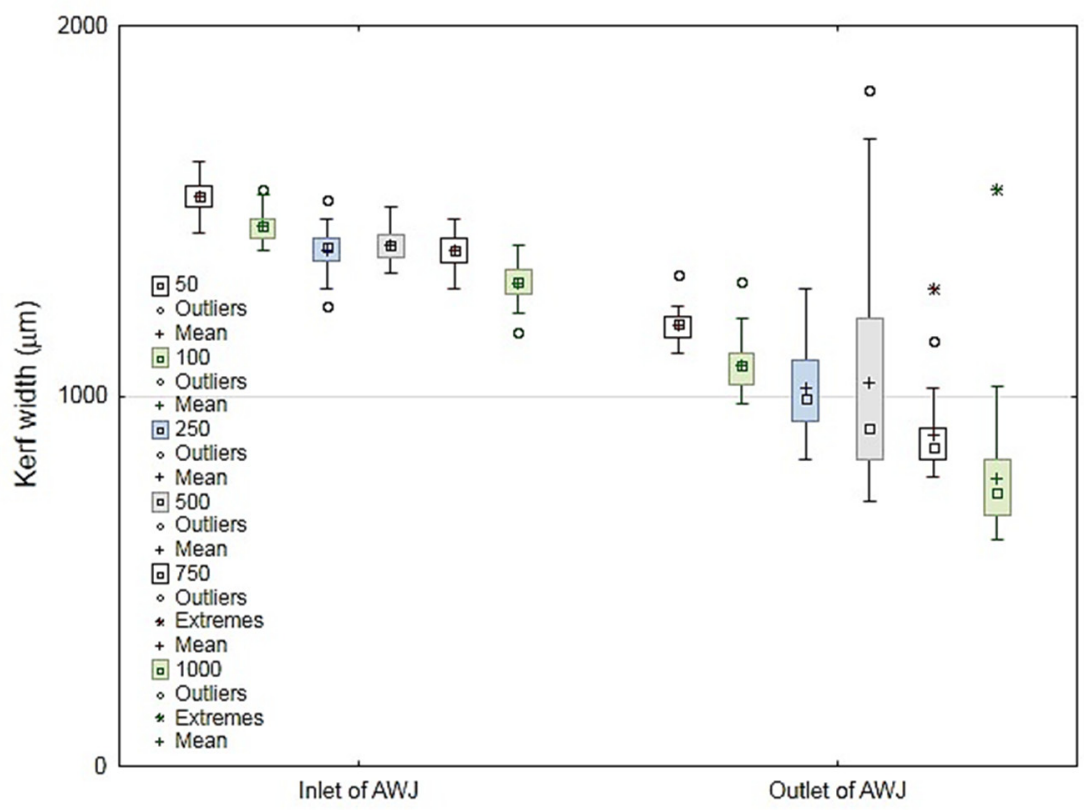

Fig. 4. Kerf width of cut by AWJ technology of polymeric composite material with coconut shell microparticle based filler

The cutting zone showed huge differences between $\mathrm{WJ}$ and $\mathrm{AWJ}$ as it is visible from fig. 5. A regular cut by the use of AWJ technology is evident from fig. $5 \mathrm{~A}$. An irregular cutting zone is obvious from fig. $6 \mathrm{~A}$ and B. Outlet there is obvious an area of tearing in the end of the cut. This negative state occurred at higher speeds, i.e. 500, 750 and $1000 \mathrm{~mm} / \mathrm{min}$. The water jet had not already sufficient kinetic energy for the cut and it came to a deformation leading to a material fracture. Therefore the results in fig. 3 are of higher scattering, namely up of $791.19 \%$.

A dual cutting zone is obvious from fig. 7 A, i.e. inlet is relatively smooth and outlet there are visible significant grooves. It is usual cutting zone [22]. A significant grooving of the surface (fig. 7 B) occurs in the bottom part of the cut from which a principle of AWJ cutting is visible, i.e. after the abrasive water jet impact into the composite material its penetration and water flow into the crack occur which causes its spreading. The effect of WJ and AWJ on the filler of the composite materials in the form of the coconut shell microparticles is evident from fig. 7 C, D and fig. 8 A, B. Fig. 7 C, D and E represent the cut by the abrasive water jet and it is evident that it comes to cutting of the filler. Fig. $8 \mathrm{~B}$ represents the cut by water jet without abrasive grains and it is evident that it comes to tearing partial segments of the filler by acting the kinetic energy to the cut. The difference between AWJ and WJ technology is obvious from fig. $7 \mathrm{D}$ and fig. $8 \mathrm{~B}$.

A delamination often occurs as a result of the impact with high speed of the water jet [16, 20]. The delamination is an important factor which can change a mechanical behaviour of composite systems during their technological processing which can be e.g. water jet cutting. Experiment results showed that the delamination could be caused also by an absence of abrasive grains at cutting by water jet technology.

SEM analysis of the surface and the evaluation of the kerf width certified that the abrasive water jet was much better than pure water jet. The research showed that quality cuts of polymeric composite materials could be prepared by AWJ technology [23]. 


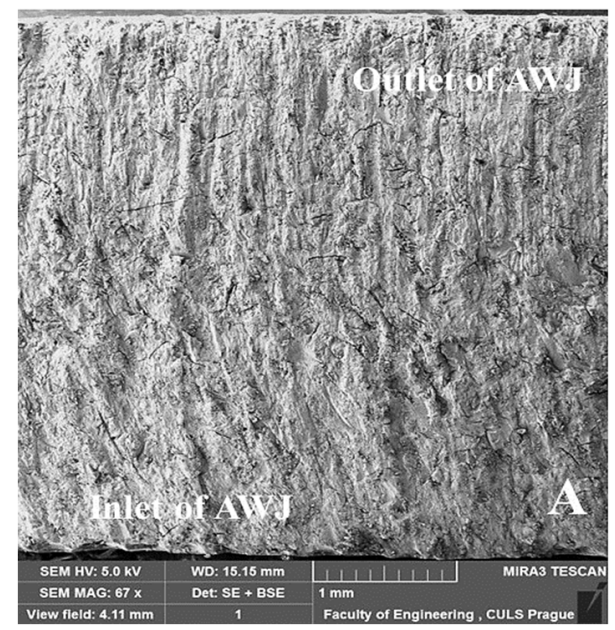

Fig. 5. SEM images of cut of composite material with coconut shell microparticles based filler A: cut by abrasive water jet (AWJ) technology, speed $750 \mathrm{~mm} / \mathrm{min}$ (MAG $67 \mathrm{x}$ )
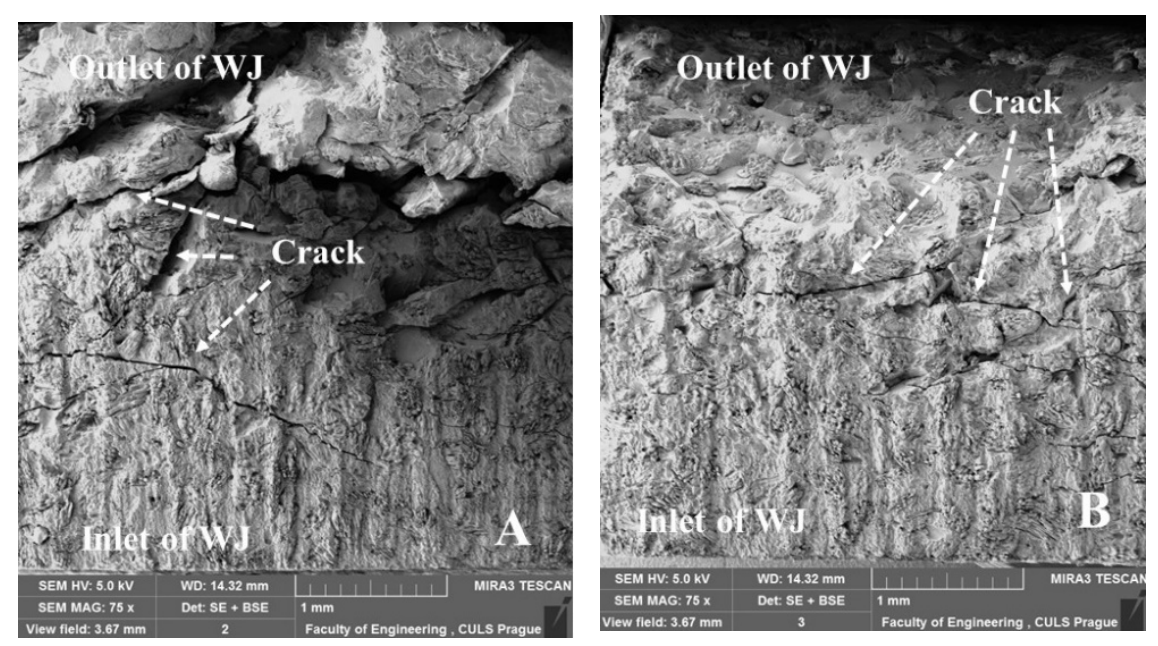

Fig. 6. SEM images of cut of composite material with coconut shell microparticles based filler A: cut by water jet (WJ) technology without abrasive grains, speed $750 \mathrm{~mm} / \mathrm{min}$ - right side of cut (MAG 75 $\mathrm{x}$ ), B: cut by water jet (WJ) technology without abrasive grains, speed $750 \mathrm{~mm} / \mathrm{min}$ - left side of cut (MAG $75 \mathrm{x}$ )

The kerf width inlet was higher than outlet. These conclusions were proved at cutting composite materials when increased removal of the material in the initial phase of the cut was manifested itself. Except for variants where it did not come to the cut but to the destruction of the material due to the kinetic energy acting [24]. 


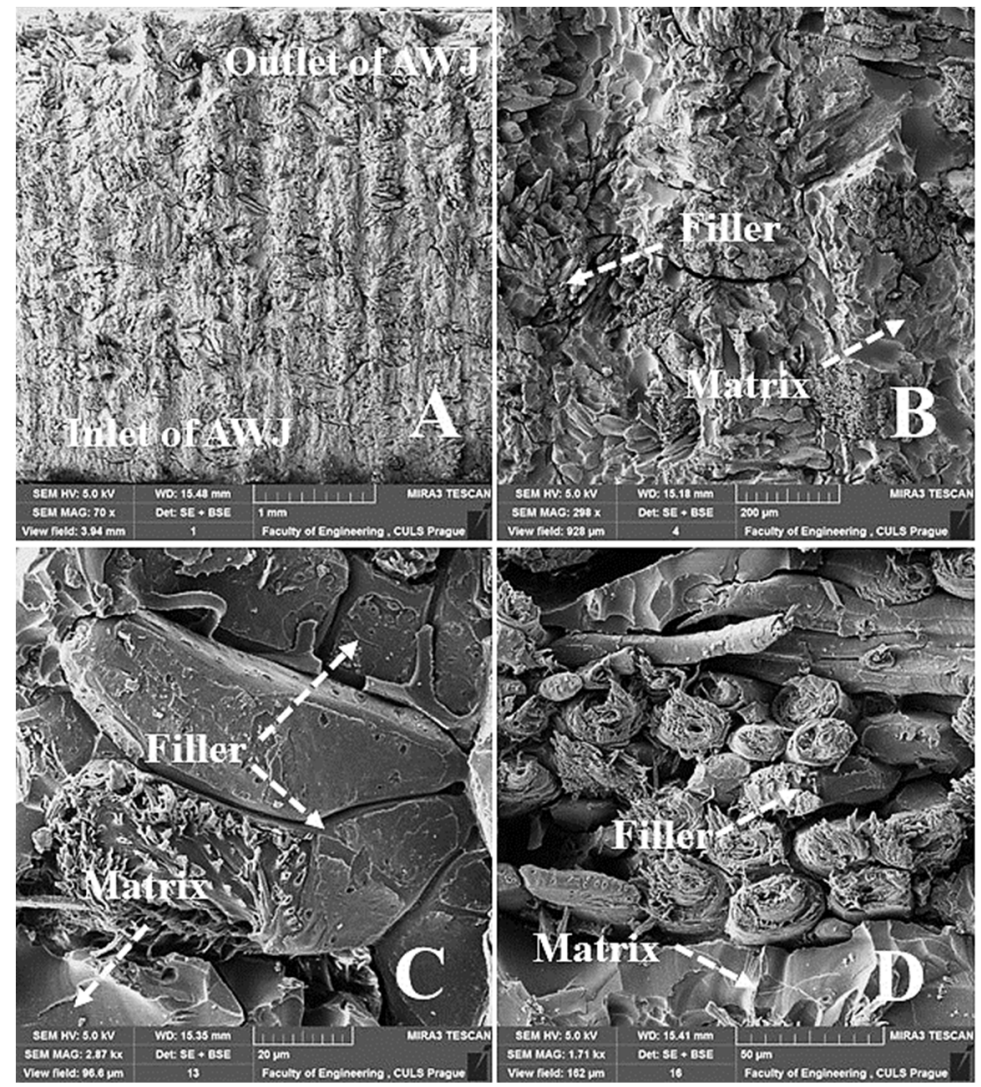

Fig. 7. SEM images of cut of composite material with coconut shell microparticle based filler, speed $100 \mathrm{~mm} / \mathrm{min}$ : A: cut by abrasive water jet technology (AWJ) (MAG $70 \mathrm{x}$ ), B: detailed view on cut by abrasive water jet technology (AWJ) (MAG 298 x), C: cut of woody coconut shell microparticle by AWJ technology- transverse orientation (MAG $2.87 \mathrm{kx}$ ), D: cut of woody coconut shell microparticle by AWJ technology - longitudinal orientation (MAG $1.71 \mathrm{kx}$ )
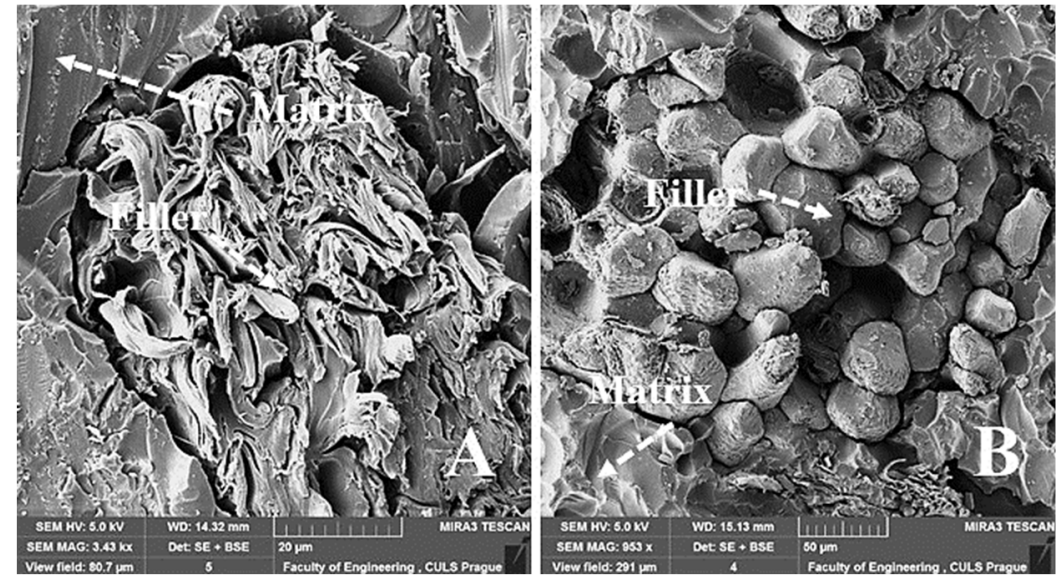

Fig. 8. SEM images of cut of composite material with coconut shell microparticle based filler, speed $100 \mathrm{~mm} / \mathrm{min}$ : A: cut of bay fibre from coconut shell by AWJ technology (MAG $3.43 \mathrm{kx}$ ), B: cut of woody coconut shell microparticle by WJ technology - longitudinal orientation (MAG $953 \mathrm{x}$ ) 


\section{Conclusions}

The research dealing with the polymeric composite material with the filler based on coconut shell microparticles machined by means of unconventional technology, i.e. the abrasive water jet (AWJ) and the water jet (WJ) proved a quiddity of the combination of the traverse speed and the mass flow of the abrasive grains to the efficiency of the cut and connected cut surface. The significant destruction of the material occurred under unsuitable cutting conditions and at the absence of the abrasive grains in the water jet inlet, i.e. on the bottom side of the cut.

Tested composite boards serve as a design element in the furniture industry due to their properties and use of the natural filler potential, i.e. an upper functional board which can substitute synthetical lamino.

This paper has been made with the assistance of the grant IGA TF CZU (Research on mechanical properties of polymeric composite materials cut by water jet, No. 31140/1312/313112).

\section{References}

1. M. Zieleniewska, M.K. Leszczynski, L. Szczepkowski, A. Bryskiewicz, M. Krzyzowska, K. Bien, J. Ryszkowska, Development and applicational evaluation of the rigid polyurethane foam composites with egg shell waste. Polymer Degradation and Stability, vol. 132, 78-86 (2016)

2. D.A. Oliveira, P. Benelli, E.R. Amante, A literature review on adding value to solid residues: egg shells. Journal of Cleaner Production, vol. 46, $42-47$ (2013)

3. J.M. Badanoa, C. Betti, I. Rintoulb, J. Vich-Berlanga, E. Cagnola, G. Torres, C. Vera, J. Yori, M. Quiroga, New composite materials as support for selective hydrogenation; egg-shell catalysts. Applied Catalysis A: General 390, 166-174 (2010)

4. A. Ruggiero, P. Valášek, M. Müller, Exploitation of waste date seeds Phoenix dactylifera in form of polymeric particle biocomposite: Investigation on adhesion, cohesion and wear. Composites: Part B, vol. 104, 9-16 (2016)

5. C Č. Mizera, D. Herák, P. Hrabě, M. Müller, A. Kabutey, Mechanical Behavior of Ensete ventricosum Fiber Under Tension Loading. Journal of Natural Fibers, vol. 14, 287-296 (2017)

6. G. Koronis, A. Silva, M. Fontul, Green composites. A review of adequate materials for automotive applications. Composites: Part B, vol. 44, 120-127 (2013)

7. C.A. Kakou, F.Z. Arrakhiz, A. Trokourey, R. Bouhfid, A. Qaiss, D. Rodrigue, Influence of coupling agent content on the properties of high density polyethylene composites reinforced with oil palm fibers. Materials and Design, vol. 63, 641-649 (2014)

8. X. Lu, M. Qiu Zhang, M. Zhi Rong, G. Shi, G. Cheng Yang, Melt processable composites of sisal. Composites Science and Technology, vol. 63, 177-186 (2003)

9. X. Zhao, R. Li, S-L. Bai, Mechanical properties of sisal fiber reinforced high density polyethylene composites: Effect of fiber content, interfacial compatibilization, and manufacturing process. Composites: Part A, vol. 65, 169-174 (2014)

10. A.S. Doumbia, M. Castro, D. Jouannet, A. Kervoëlen, T. Falher, L. Cauret, A. Bourmaud Flax/polypropylene composites for lightened structures: Multiscale analysis of process and fibre parameters. Materials and Design, vol. 87, 331-341 (2015)

11. A.A. Nasir Abdul, A.I. Azmi, A.N.M. Khalil Measurement and optimisation of residual tensile strength and delamination damage of drilled flax fibre reinforced composites. Measurement, vol. 75, 298-307 (2015) 
12. M.P. Ho, H. Wang, J.H. Lee, C.K. Ho, K.T. Lau, J. Leng, D. Hui Critical factors on manufacturing processes of natural fibre composites. Composites Part B: Engineering, vol. 43, 3549-3562 (2012)

13. H-Y. Cheung, M-P. Ho., K-T. Lau, F. Cardona, D. Hui. Natural fibre-reinforced composites for bioengineering and environmental engineering applications. Composites: Part B, vol. 40, 655-663 (2009)

14. K.A. Iyer, J.M Torkelson Green composites of polypropylene and eggshell: Effective biofiller size reduction and dispersion by single-step processing with solid-state shear pulverization. Composites Science and Technology, vol. 102, 152-160 (2014)

15. M. Müller, P. Valášek Research on aluminium alloy alcu4mg surface machined by abrasive water jet. Manufacturing technology, vol. 17, 925-930 (2017)

16. M. Müller, R. D'Amato, A. Rudawska Machining of polymeric composites by means of abrasive water-jet technology. In 16th international scientific conference: engineering for rural development 24.05.2017, Latvia univ agr, fac engn, Jelgava, Latvia. Jelgava, Latvia: Latvia univ agriculture, Faculty engineering, inst mechanics, $5 \mathrm{j}$ cakstes blvd, Jelgava, lv-3001, Latvia, 121-127 (2017)

17. M. Kušnerová, J. Foldyna, L. Sitek, J. Valicek, S. Hloch, M. Harnicarova, M. Kadnar Innovative approach to advanced modulated waterjet technology. Technicki VjesnikTechnical Gazette, vol. 19 (3), 475-480 (2012)

18. S. Hloch, J. Hlavacek, K. Vasilko, J. Carach, I. Samardzic, D. Kozak, I. Hlavaty, J.J. Scucka, Klich, D. Klichava Abrasive waterjet (AWJ) titanium tangential turning evaluation. Metalurgija, vol. 53(4), 537-540 (2014)

19. J. Wang, D.M. Guo A predictive depth of penetration model for abrasive waterjet cutting of polymer matrix composites. Journal of Materials Processing Technology, vol. 121, 390-394 (2002)

20. D.K. Shanmugam, T. Nguyen, J.A. Wang Study of delamination on graphitelepoxy composites in abrasive waterjet machining. Composites: Part A, vol. 39, 923-929 (2008)

21. D.K. Shanmugam, F.L. Chen, E. Siores, M. Brandt Comparative study of jetting machining technologies over laser machining technology for cutting composite materials. Composite Structures, vol. 57, 289-296 (2002)

22. M. Hashish A model study of metal cutting with abrasive water jet. In: ASME Journal of Engineering Materials and Technology, vol. 106, 88-100 (1984)

23. E. Lemma, F.L. Chen, E. Siores, J. Wang Study of cutting fiber reinforced composites by using abrasive waterjet with cutting head oscillation. Composite Structure, vol. 57, 297-303 (2002)

24. J. Wang Abrasive waterjet machining of polymer matrix composites-cutting performance, erosive process and predictive models. Int J Adv Manuf Technol., vol. 15, 757-768 (1999) 